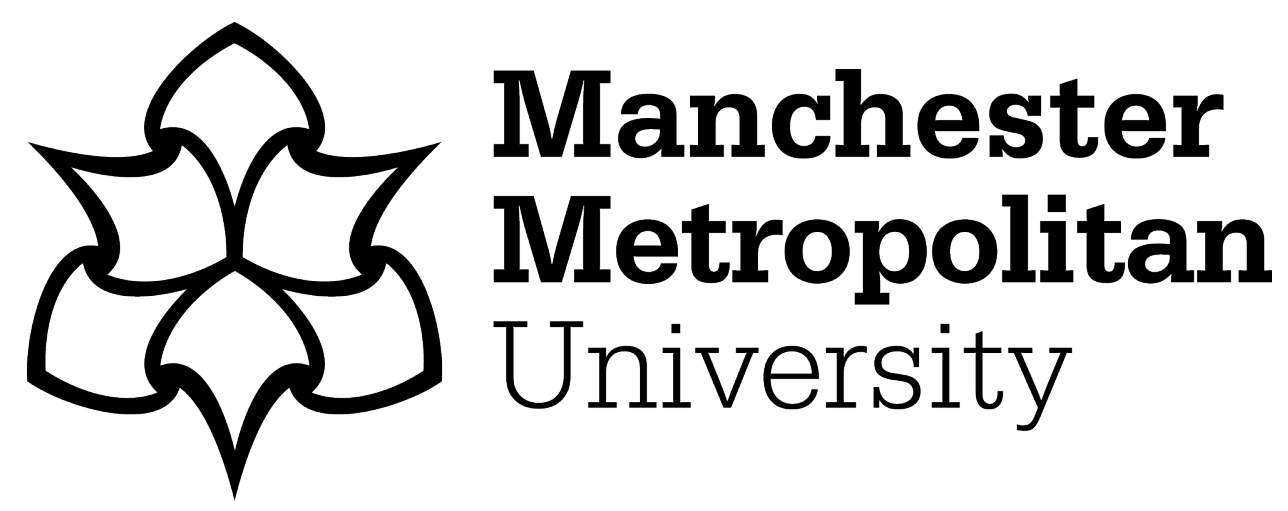

Botham, KA ORCID logoORCID: https://orcid.org/0000-0002-0610-6514 (2017) An analysis of the factors that affect engagement of Higher Education teachers with an institutional professional development scheme. Innovations in Education and Teaching International, 55 (2). pp. 176-189. ISSN 1470-3297

Downloaded from: https://e-space.mmu.ac.uk/623617/

Version: Accepted Version

Publisher: Taylor Francis

DOI: https://doi.org/10.1080/14703297.2017.1407664

Please cite the published version 


\title{
An analysis of the factors that affect engagement of Higher Education teachers with an institutional professional development scheme*
}

\author{
Kathryn Ann Botham \\ Centre for Excellence in Learning and Teaching, Manchester Metropolitan University, Manchester, UK
}

\begin{abstract}
An evaluation project was carried out to consider the factors that influence university teachers engagement with an institutional professional development scheme. Data was collected via an online questionnaire followed up by semi-structured interviews. This paper will consider those factors that encourage and act as barriers to engagement. The influence of six cross-thematic factors: Time; Institution; Culture; Management; Individual and Mentorship, on engagement will form the focus of the discussion. The report concludes that the key factor influencing engagement was the presence of intrinsic motivation. Extrinsic motivation was a less effective motivator for $\mathrm{HE}$ teachers lacking intrinsic motivation.
\end{abstract}

\section{KEYWORDS}

Teaching and learning; Professional recognition; UK Professional Standards Framework; Higher Education Academy; HEA Fellowship; Engagement; Motivation; Continual Professional Development

\section{Introduction}

This study investigates the factors that influence university teachers' engagement with an institutional professional development scheme aligned to the UK PSF (UK Professional Standards Framework) (Higher Education Academy [HEA], 2011) and leading to Higher Education Academy (HEA) Fellowship. The scheme under investigation is located within a large Post-92 Higher Education Institution (HEI). The scheme enables university teachers' and support staff to submit a claim for fellowship, via a critically reflective portfolio, to an institutional assessment panel. This panel is able to award all categories of HEA Fellowship (Associate, Fellow, Senior and Principal).

\section{Context and background}

Gaining engagement with teaching-focussed Continuous Professional Development (CPD) from some Higher Education (HE) teachers can be challenging. Although the majority of $\mathrm{HE}$ teachers acknowledge the benefits of teaching-related CPD, many still fail to engage (King, 2004; Rothwell, 2009). Rothwell and Herbert (2007) found that the least experienced staff were more likely to engage with CPD, and staff who had been employed for many years often failed to engage (Rothwell \& Herbert, 2007). 
This paper will investigate the factors that motivate HE teachers to engage with an HEA accredited CPD scheme and the factors that can act as barriers to engagement.

\section{Literature review}

This paper considers the opinions of HE teachers who engaged with an institutional CPD scheme leading to HEA Fellowship. This scheme has two main measures of engagement. Firstly, 'initial engagement' when HE teachers register on the scheme and then 'submission', when the application is submitted. Two groups of applicants have been identified:'Successful Applicants' who submit their applications on time, and 'Deferred Applicants', who register but then fail to submit or repeatedly defer submission. This study investigated the factors that influenced these differing behaviours.

Seden and Cope (2009) suggest that a key factor influencing engagement with CPD is 'dual professionalism. Dual professionals have both a discipline focus and a teacher focus to their practice. Wood (2008) reported that HE teachers prioritise discipline specific over teaching focussed CPD. Deaker, Stein, and Spiller (2016) recommend that incorporating a discipline focus within professional development may reduce some resistance to teaching focussed development activities.

Motivation is also a key factor influencing HE teachers' engagement in CPD. Mullins (2016) defines two forms of motivation: Intrinsic and Extrinsic. Intrinsic refers to gaining psychological self-reward through personal achievement and recognition, whereas extrinsic motivation refers to gaining tangible rewards such as improved salary and promotion. External motivators are generally less potent than an individual's intrinsic wish to develop or gain recognition (Knowles, 1998; Mullins, 2016). Crawford (2010) found that engagement with CPD was dependent on $\mathrm{HE}$ teachers 'proactively engaging with the processes and opportunities' (p. 193) and having 'agency' such as having a personal philosophy that values professional development.

The intrinsic need for recognition has been shown to be a key motivator for engagement with CPD. Hall (2009) commented that some HE teachers wish to be valued for their work and will engage in teaching focussed CPD to achieve this. Botham (2017) found that recognition as a teaching and learning leader was a key desired outcome for colleagues engaging in a CPD Scheme.

A number of studies have also found that a lack of extrinsic reward for teaching activities discourages some HE teachers from engaging with teaching-focussed CPD. Kynaston and Maynard (2009) suggest that the lack of a career structure enabling HE teachers to gain promotion through teaching is a key disincentive for engagement with teaching focussed CPD. King (2004) found that 53\% of their respondents felt that an emphasis on research was the key barrier to their engagement in teaching focussed CPD. They also suggested that career progression within UK HEl's relied on having a strong research profile and although teaching and learning related activities were applauded they were worth little in relation to promotion. Evidence suggests that this is still the case over a decade later (BiS, 2015, p. 12). 


\section{Aims of study}

This paper will analyse the factors that influenced HE teachers' engagement with the scheme based in a large teaching intensive HEl. The specific objectives of the study were to evaluate:

(1) The reasons applicants engage with the scheme

(2) The reasons underlying deferred applications (barriers)

(3) The effectiveness of the support mechanisms for applicants

\section{Method}

This study considers the views of key stakeholders on the issue of engagement with this CPD scheme. A mixed methods approach, including an initial questionnaire to establish key themes, followed by semi-structured interviews to expand the initial survey findings was used. This method was chosen because it allows patterns and relationships within the data to be revealed more clearly (Chatterji, 2005). The questionnaire identified key themes and the interviews facilitated a deeper exploration of these themes (Robson, 2011). The project gained full ethical approval and all participants gave full informed consent and were assured of anonymity and confidentiality.

The sample incorporated all grades of HE teachers who had engaged with the scheme. In addition, HE Departmental Managers were also approached to take part in the study as they were in a key position to influence the engagement of their staff. The sample was divided into two main groups:

Group 1: HE teachers registering with the scheme between September 2013 and May 2015. This group was divided into two sub-groups:

- 1A: Applicants who submitted applications. $(n=47)$ (Successful applicants)

- 1B: Applicants who deferred submission of their application on more than two occasions ( $n=29)$ (Deferred applicants)

Group 2: HE managers - Heads of Department (HoD) $(n=39)$.

\section{Stage 1: questionnaires}

Online questionnaires were used to gain opinion on the scheme from as many respondents as possible. Three formats of questionnaires were created, each adapted to align with the different respondents' perspectives and their record of engagement with the scheme. Questions focussed on why they had engaged/disengaged with the scheme and what things had been a barrier to them submitting on time.

The questionnaire responses were analysed using thematic analysis (Braun \& Clarke, 2006; Graneheim \& Lundman, 2004; Robson, 2011). The thematic coding process described by Robson (2011) was adapted for this purpose and produced initial thematic networks. Robson (2011) describes a thematic network as the'fitting together of the themes into one or more maps or networks' (p. 483).

The completion rate for the questionnaires ranged from 44 to $74 \%$ (see Table 1). 
Table 1. Questionnaire response rate.

\begin{tabular}{lccc}
\hline & & \multicolumn{2}{c}{ Completions } \\
\cline { 3 - 4 } Questionnaire group & Sample $(n)$ & Total $(n)$ & Percentage (\%) \\
\hline 1A: Successful applicants & 47 & 35 & 74 \\
1B: Deferred applicants & 29 & 17 & 59 \\
2: Heads of department & 39 & 11 & 28 \\
\hline
\end{tabular}

Two thematic networks were identified from the questionnaire data; the first of these, teaching and learning practice development, has been discussed elsewhere (Botham, 2017). The second, 'engagement', will be the focus of this paper. This initial network identified the topics that were explored further in the stage 2 interviews.

\section{Stage 2 interviews}

There are six faculties in the institution (coded A-F) and five were represented in the interviews (see Table 2). Selection aimed to provide a group of interviewees covering a range of faculties and a range of categories of Fellowship. Only volunteers from the successful applicants group and the Heads of Department group were interviewed, as none of the deferred applicants group (1B) volunteered to participate. The interviews focussed on the reasons why applicants had engaged in the scheme, any barriers they had overcome and their perception of why others may have deferred their applications.

\section{Limitations}

As the author/interviewer is the CPD Scheme Lead and a member of the Centre for Excellence in Learning and Teaching (CELT) it is important to acknowledge potential bias. Although all attempts were made during the review process to be objective when reviewing the data.

The lack of engagement in the interviews from Group 1B also means the barriers must be drawn solely from the survey and the perceptions of successful applicants.

\section{Results}

Following thematic analysis of the interviews a final thematic network was identified which consisting of two main categories: Factors encouraging engagement and Factors leading to

Table 2. Characteristics of interviewees.

\begin{tabular}{llll}
\hline Applicant & \multicolumn{1}{c}{ Role } & Faculty & HEA category achieved \\
\hline A1 & Academic Leader & F & SFHEA \\
A2 & Senior Learning and Teaching Fellow & A & PFHEA \\
A3 & Senior Lecturer & A & FHEA \\
A4 & Faculty Student Support Officer & E & FHEA \\
A5 & Principal Lecturer & C & SFHEA \\
HoD & & & \\
HoD1 & Head of Department & A & Nil \\
HoD2 & & B & SFHEA \\
HoD3 & & D & Expression of interest \\
HoD4 & & A & Expression of interest \\
\hline
\end{tabular}


deferral/non-engagement. A number of further sub-categories that spread across the two main categories were identified forming a matrix. Table 3 illustrates this matrix network.

\section{Discussion}

The following discussion is structured around the six sub-categories (see Table 3).

\section{Time}

Following analysis of the questionnaires, 'time' was commonly identified as a potential barrier to engagement. All the 'deferred applicants' (1B) commented that the lack of free time and workload pressure had contributed to the deferral of their application. Four successful applicants ( $1 \mathrm{~A})$ also suggested that time limitations had been a potential barrier. However, they successfully managed the time issues and submitted on time (Wood, 2008). 'Time' was further investigated in the interviews and three themes within this sub-category were identified.

\section{Lack of time}

Lack of time, workload pressures and conflicting priorities were factors that could act as a barrier to engagement. All interviewed successful applicants identified this as a factor that could potentially have been a barrier.

staff they always feel that they are busy ..., it's the matter of people being stretched, having to prioritise things and this [application] takes a backseat. (Applicant 2)

The factor of lack of time has been discussed in other studies. King (2004) found that $84 \%$ of respondents stated that 'lack of time and pressures from other priorities' (p. 27) was the key barrier to their engagement with CPD.

\section{Need for deployed hours}

To provide some context here, in the HEl being studied there was no formal policy for allocating dedicated hours to prepare a Fellowship application. Mixed opinions of the benefits of the allocation of protected time to complete an application was evident in the questionnaire responses and was confirmed by the interviewees. Some suggested that allocated hours were not appropriate because:

- staff should be able to balance their workload and complete the application within their current hours (HoD1).

- Fellowship has benefits for the applicants due to recognition of their practice and they should prioritise the time over other commitments (Applicants 2, 3, 4, 5).

Whilst others suggested that deployed hours may be useful because:

- Their annual allocated time for scholarly activities gets used for other day to day activities (HoD2, Applicant 1).

- Staff struggle with the flexibility of the PSF and let other things 'get in the way' (HoD2). 


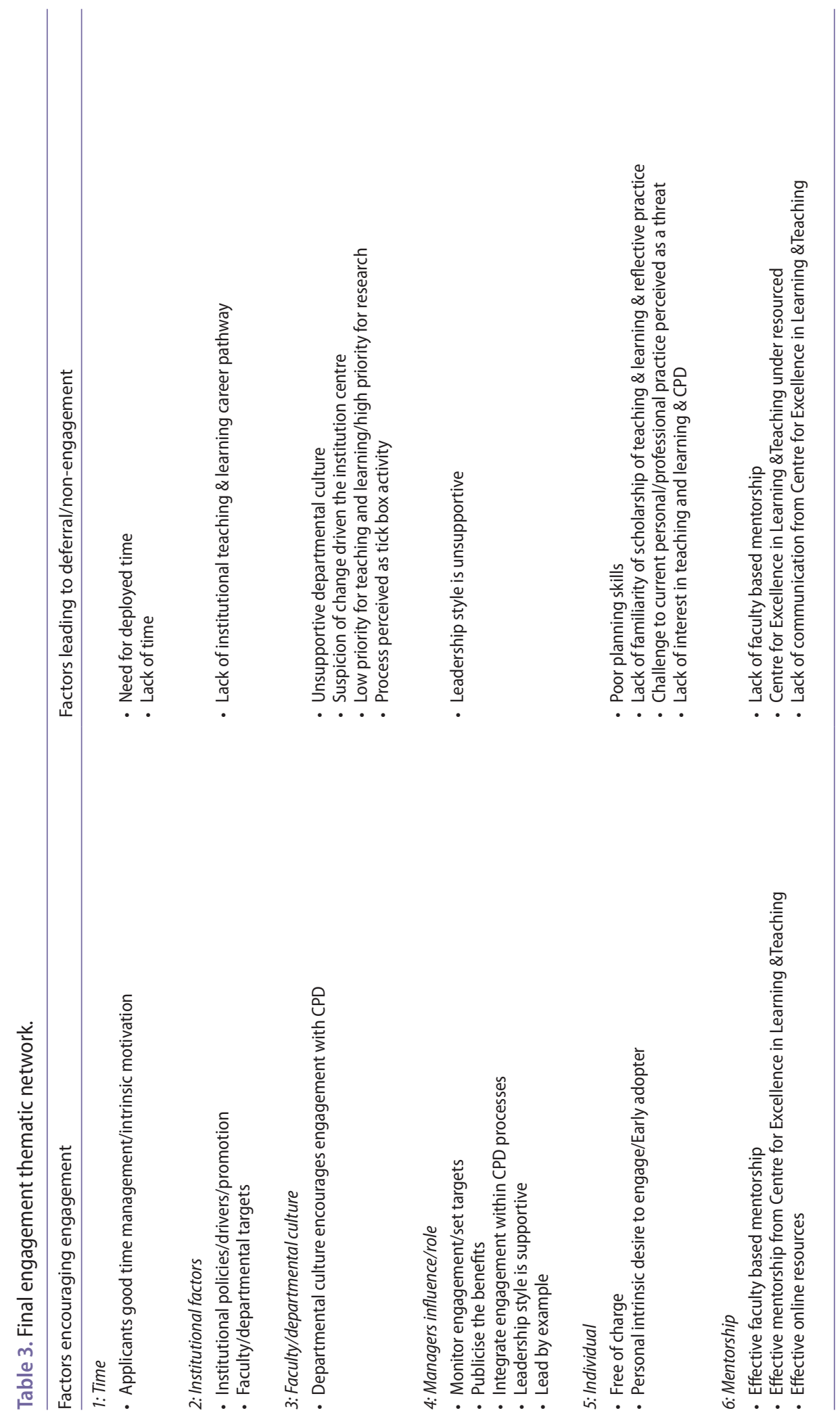




\section{Applicants' intrinsic motivation}

Although a number of successful applicants recognised that time was an issue for some colleagues, none actually requested deployed hours. They deemed the process a personal priority and this intrinsic motivation encouraged them to prioritise the time over and above other calls on their time. Applicant 2 summarises this stating, 'I wouldn't have expected to [get time]. I see this very much as being part of my role of learning and teaching leadership. I wouldn't have asked for any'.

Wood (2008) confirmed that time was mentioned by all her interviewees $(n=11)$. Her findings also confirm the three issues demonstrated in this study: a lack of time linked to workload and other priorities; a need to just 'be given time' and willingness for motivated staff to 'find time' even if they were busy. Crawford (2010) supports the idea that internal motivation and a personal agency to engage will enable someone to overcome the barrier of limited time.

\section{Institutional factors}

\section{Career enhancement/institutional drivers/policies}

Career Enhancement: During stage 1 nine applicants identified that they were aware that having a Recognised Teaching Qualification (RTQ) was now part of many HEl career pathways. This factor was particularly important to staff considering moving to other institutions as Fellowship was appearing in job descriptions and being recognised nationally as an indicator of competence.

Institutional Driver: During stage 1 eleven successful applicants identified that they were influenced to engage in the scheme by an institutional requirement to gain a RTQ. Within the interviews both groups suggested that the institution was becoming vigilant in ensuring staff complete this requirement (Applicant 1, 2, 3, 5). The HoDs group also identified the inclusion of RTQ data within the institution's HESA return as a factor that had influenced this change in priority (HoD1, 4). HoD2 however felt that this driver should be resisted, as it tended to encourage rubber-stamping rather than creating opportunities for staff to engage in true career enhancement activities.

\section{Faculty/departmental targets}

The potential benefits of institutional targets as an extrinsic motivator for engagement were discussed in the interviews. The majority of respondents supported the setting of targets. HoD1 had set a departmental target of $100 \%$ and expressed disappointment with the lack of a clear institutional target, as this had 'enabled staff to opt out'. HoD4 supported the use of targets, but set a lower $80 \%$ target as an encouragement without 'too much pressure'.

Turner et al. (2013) also reported mixed opinions on the benefits of targets. They report that some institutions set ambitious targets of $100 \%$ Fellowship and others did not seeing the benefit in setting any targets.

\section{Lack of a learning and teaching career structure}

This was a new sub-theme from the interviews and was predominantly raised by the HoD group. HoD1, 2 and 4 reported that a lack of an institutional teaching and learning career structure was influencing staff priorities (see section high priority for research activities). HoD4 stated 
promotions to Readerships and Professorships are based on your research.... not on teaching quality ... We are having a round of Professors' interviews next week and we are trying to get the teaching element incorporated but it is definitely secondary to the research presentation.

Current evidence suggests that in many HEl's research activity leads more directly to promotion and career enhancement with ambitious HE Teacher staff tending to focus on research more than teaching (BiS, 2015, p. 12). Kynaston and Maynard (2009) suggest 'the lack of career structures for those who wished to advance themselves in teaching and learning hinders further CPD development' (p. 59). The development of career structures incorporating learning and teaching pathways may therefore encourage ambitious staff to engage with teaching focussed CPD schemes if it will also support their promotion.

\section{Faculty/departmental culture}

\section{Supportive departmental culture}

A supportive departmental culture appeared to encourage engagement with the scheme. HoD2 and Applicant 2 were from a department with high scheme engagement and identified that a supportive culture encouraged their staff to engage. The cultural factors were summarised as being 'part of our professional identity and practice' (HoD2) and the presence of a 'supportive and effective leader' (Applicant 2). The department in question consisted of healthcare professionals who embedded a culture of professional development within their practice. This created intrinsic motivation for staff to engage with new CPD opportunities. Applicant 2 summarised the additional value of a supportive leader stating that, 'they have strong leadership from someone who has a clear departmental strategy'.

\section{Unsupportive departmental culture}

Applicant 3 reported that the culture within their department was not supportive of colleague's engagement with the scheme. They described a culture linked to a fear of failure, 'people feel very vulnerable at the moment ... people are scared of the outcome and that they will end up looking embarrassed in front of colleagues. They combined this fear with a HoD leadership style where the 'approach isn't as supportive as it could be. It's a bit like a stick'.

The two contrasting approaches to leadership described above could potentially have an impact on engagement. King (2004) identified that a culture that values CPD and rewards CPD is an important factor in encouraging engagement. However, in Applicant 3's case their intrinsic motivation seemed to overcome this potential barrier.

\section{Suspicion of change coming from the centre/perception of managerialism}

Quinn (2012) and Deaker et al. (2016) reported that fear and suspicion of the motive underpinning institutional initiatives linked to professional development could reduce HE teachers' engagement. This issue was mentioned within the deferred applicants (1B) questionnaire responses and became clearer following the interviews. A number of perceived but difficult to measure barriers were identified:

- 'That mental barrier and that suspicion about anything coming from the centre', with resistance most commonly coming from the staff that have been here the longest (HoD1). 
- Suspicion that 'something nefarious is going on' (HoD4).

- 'I have a PhD in this subject, I've taught the subject for 20 years, I know what I'm doing, I have consistently high ISS scores and good NSS Scores' (HoD4).

- 'How dare anyone challenge my ability' (HoD1).

Cultural and political perceptions are difficult to change within an organisation (Bates, 2010). Clear communication and increased engagement with these staff groups from academic developers is often needed to change the perceptions described above. This approach proved to be effective within this institution. One department had previously not engaged with the scheme due to the fears expressed above. The scheme leader developed an alliance with the department's teaching and learning lead and introduced bespoke mentorship workshops supported by the departments champion. This approach successfully encouraged the department to engage and they quickly moved from having no Senior Fellows to having the highest number in the institution. Kynaston and Maynard (2009) found that the strategy of engaging departmental champions was also a critical success factor in the development of their institutional scheme.

\section{Low priority to teaching and learning/high priority for research activities}

A low priority to engage with the scheme was evident in some applicants. For these colleagues extrinsic motivation appeared to be the required motivator and this was lacking within their departmental culture. All interviewees reported that a low priority towards teaching was inhibiting some colleague's engagement with the scheme. HoD1, 2 and 3 expressed concern that within some parts of the institution teaching had a relatively low priority which was often linked to tension between a high priority for research and a lower priority for teaching.

A number of factors were resulting in a greater prioritisation of research activities:

- Promotion to higher HE Teacher grades (readers/professors) was predominantly research focussed (HoD2, 4)

- A requirement for all institutional Teaching staff to gain a PhD (HoD1, 4, Applicant 5)

- The requirement in some faculties for all staff to engage with the Research Excellence Framework (HoD4)

King (2004) identified, pressure to engage with research coupled with the fact that key promotion opportunities required an 'international research reputation' (p. 27), as a key barrier to HE teachers undertaking teaching focussed CPD. It was the second most common barrier after 'Time' and identified by 53\% of her respondents. Quinn (2012) and Crawford (2010) also describes the research agenda as a being counterproductive with regard to engagement with professional development.

\section{Manager's influence on engagement}

Publicise the positive aspects of the scheme/integrate into performance review (PDR) The influence of manager as the performance development (PDR) reviewer of their staff was identified as something that could stimulate staff engagement. All managers interviewed reported that they already publicised the positive aspects of the scheme within the PDR process and incorporated conversations around gaining fellowship within the process. 
Applicants 1, 2, 3 and 5 all confirmed that gaining Fellowship was included as a goal in their PDR action plan.

\section{Supportive/unsupportive managers}

Senior Managers have a central role in supporting these schemes and encouraging engagement from their staff. Low engagement in the scheme by the managers themselves was apparent, with only six senior institutional managers registering with the scheme between September 2013 and summer 2015.

All applicants, apart from Applicant 3, suggested that their department managers were supportive of their application. The level of support ranged from writing the reference (Applicants 1, 2), to actively supporting the applicant and acting as a mentor (Applicants 4, 5). The exception was Applicant 3 who reported that they had no support from either their line manager or HoD.

Turner et al. (2013) found that 'support from senior managers was seen by many HE Teacher staff as being crucial' (p. 31) in the success of a CPD scheme. Other research supports the fact that strong leadership from senior managers leads to good engagement with institutional schemes (Bradley, 2014; Gibbs, Knapper, \& Piccinin, 2008; Spowart, Turner, Shenton, \& Kneale, 2015; Turner et al., 2013). Platt and Floyd (2015) evaluated the role of HE managers in supporting engagement with CPD schemes and concluded that 'staff engagement with L \& T initiatives are enhanced by an HE manager who implements the types of leadership activity that creates a culture where $L \& T$ is openly valued, encouraged and recognised' ( $p$. 9).

The conclusion from this study must be that a supportive departmental head is helpful but perhaps not essential. If applicants are personally motivated they can still succeed with or without support from their manager as demonstrated by Applicant 3. The importance of this personal motivation was acknowledged by four of the applicants with Applicants 2, 4, 5 , and HoD2 all recognising that their key motivation to apply was a personal wish to engage with the scheme as an early adopter.

HoD2 and Applicants 1, 2 and 3 also reported that having a manager leading by example had a positive impact on staff engagement. The HoDs identified two factors that could be influencing the low engagement from managers.

- Some managers 'don't think it's [the scheme] got anything to do with them. They see the benefits ... for their staff and realise it's a university imperative but they may not see their own engagement as having a benefit' (HoD3).

- They 'are not teaching as much and are unsure how to show their impact. A lot of the language used is around dealing with students' (HoD 2).

The encouragement of managers to personally engage with the CPD Scheme appears to have the potential to act as another extrinsic motivator for engagement.

\section{Individual factors}

\section{Lack of familiarity with scholarship of teaching and learning, reflective practice and reflective writing}

This was a new sub-category that emerged during the interviews. Two key challenges for some applicants emerged: 
- A difficulty with the reflective style of writing required for an application (HoD1, 2, Applicants 1, 2, 5).

- The need to demonstrate a scholarly approach when completing an application (HoD2, Applicant 1, 2,5).

Many institutions are targeting experienced teachers who have not previously engaged with teaching-focussed CPD to engage with their recognition schemes. This lack of prior engagement with the scholarship of teaching had resulted in this group finding both reflective writing and the engagement with teaching theory challenging and a barrier to completing a successful application. The development of more supportive schemes linked to flexible informal and formal developmental activities may be a more effective way of supporting this group of staff.

\section{Challenge to current practice}

A number of interviewees reported that some colleagues were not engaging with the scheme because they perceived the process as a challenge to their current practice and viewed it as a threat. HoD1, 2, and 4 reported that staff perceived that engaging with the scheme placed their current practice under scrutiny and could result in its effectiveness being challenged.

Some interviewees (HoD3, Applicant 3) reported that some colleagues also perceived a threat through a fear of failure. HoD3 suggests that this may be a particular factor for senior staff. 'People may not engage with it because they don't want to fail, they don't want to be seen to fail by their peers' (HoD3). It is therefore vital that all applicants are appropriately supported throughout the process and it is clear that the scheme guarantees confidentiality and anonymity to the applicants.

\section{Lack of interest in teaching and learning}

HoD1, 2, and 4 felt that some colleagues inherently have a lack of interest in teaching and learning issues and a consequential lack intrinsic motivation to engage in teaching focussed CPD. A number of factors appear to underpin the reluctant engagement with the PSF Scheme.

- Staff with a practitioner backgrounds such as artists, don't always view teaching and learning as a priority that is relevant for them (HoD2).

- The research agenda takes priority (HoD4).

- Colleagues see themselves as good teachers and see no relevance of teaching CPD (HoD1, 4).

- Strategies to increase RTQs are viewed with suspicion (HoD1, 4).

\section{Mentorship}

The majority of the responses here were specific to the institution and not relevant for this paper. However, one key finding was the real value of ensuring that applicants received some mentorship from within their own departments often combined with mentorship from Academic Developers. This approach was particular effective for colleagues in Departments that were reluctant to engage with central CPD units such as CELT. 


\section{Conclusion}

\section{The reasons applicants engaged with the scheme}

All applicants interviewed here were early-adopters and appeared to all have inherent intrinsic motivation to engage with the scheme. They had a wish to develop as a teacher, or gain recognition for their teaching and learning activities. Extrinsic motivation such as institutional policies and PDR goals contributed in initiating engagement but were not the key driver of success.

\section{The potential reasons underlying deferred applications (barriers)}

Many factors were identified as barriers to engagement. The most potent barrier was a lack of intrinsic motivation associated with a lack of interest in teaching focussed CPD. This attitude was generally combined with a perceived lack of time, conflicting priorities (particularly research) and a lack of reward from a predominantly research focussed career structure. Other factors identified were the lack of targets, unsupportive departmental cultures or management, suspicion of change that challenged current practice and the lack of familiarity with teaching and learning scholarship and reflective practice.

\section{The effectiveness of the support mechanisms for applicants}

Many applicants suggested that faculty based mentorship was a key component of success and suggested that combined mentorship from Faculty and CELT mentors was the best option. In departments where engagement was more reluctant, bespoke mentorship from the scheme lead, mediated by a faculty-based champion seemed to be an effective alternative.

In conclusion, it would appear that intrinsic motivation plus effective mentorship were the key success factors leading to applicants successfully completing their application. Extrinsic motivators such as effective departmental support and PDR targets were useful additional motivators but appear less powerful on their own. Colleagues with a lack of intrinsic motivation appeared more liable to perceive a lack of time, conflicting priorities related to research together with a lack of teaching and learning career structure as a reason to not prioritise engagement with this type of teaching focussed CPD. Other factors discussed here a more nebulous and culturally based and therefore more difficult to address. Attitudes tend to be slow to change (Bohner \&Wänke, 2002) and the respondents have reported a number of perceived threats linked to the professionalisation of HE teachers. Institutions therefore will need to consider how they may best change these perceptions and support staff through this change.

\section{Disclosure statement}

No potential conflict of interest was reported by the author. 


\section{Notes on contributor}

Kathryn Ann Botham is an HE Academic Developer and Principal HEA Fellow. She is an HEA accreditor and external assessor for a number of institutional PSF schemes. She involved in single institution and cross institutional research related to the evaluation of institutional PSF Schemes; Effective support for disabled students in practice and within the university setting; Inclusive curriculum development and delivery.

\section{References}

Bates, T. (2010). New challenges for universities: Why they must change. In U.-D. Ehlers \& D. Schneckenberg (Eds.), Changing cultures in higher education (pp. 15-25). Berlin: Springer.

BiS (Department for Business, Innovation \& Skills). (2015). Fulfilling our potential:Teaching excellence, social mobility and student choice. Retrieved from https:/www.gov.uk/government/uploads/ system/uploads/attachment_data/file/474227/BIS-15-623-fulfilling-our-potential-teachingexcellence-social-mobility-and-student-choice.CPDf

Bohner, G., \& Wänke, M. (2002). Attitudes and attitude change. Hove: Psychology Press.

Botham, K. A. (2017). The perceived impact on HE teachers' teaching practice of engaging with a Higher Education Institution's professional body recognition. Innovations in Education and Teaching International, (published online). Retrieved from http://www.tandfonline.com/doi/full/10.1080/14 703297.2017.1371056

Bradley, S. (2014). 'Not a means to an end but a genuinely rewarding process' - A personal response to 'UKPSF: A vehicle for development or hierarchical ladder?' Educational Developments, 15, 19-20. Retrieved from http://www.seda.ac.uk/resources/files/publications_187_Ed\%20Devs\%2015.2\%20 FINAL.CPDf

Braun, V., \& Clarke, V. (2006). Using thematic analysis in psychology. Qualitative Research in Psychology, 3, 77-101. Retrieved from http://eprints.uwe.ac.uk/11735/2/thematic_analysis_revised

Chatterji, M. (2005). Evidence on "What works": An argument for extended-term mixed-method (ETMM) evaluation designs. Educational Researcher, 34, 14-24.

Crawford, K. (2010). Influences on academics' approaches to development: Voices from below. International Journal for Academic Development, 15, 189-202.

Deaker, L., Stein, S. J., \& Spiller, D. (2016). You can't teach me: Exploring academic resistance to teaching development. International Journal for Academic Development, 21, 299-311.

Gibbs, G., Knapper, C., \& Piccinin, S. (2008). Disciplinary and contextually appropriate approaches to leadership of teaching in research-intensive HE teacher departments in higher education. Higher Education Quarterly, 62, 416-436.

Graneheim, U. H., \& Lundman, B. (2004). Qualitative content analysis in nursing research: Concepts, procedures and measures of trustworthiness. Nurse Education Today, 24, 105-112. Retrieved from http://www.ncbi.nlm.nih.gov/pubmed/14769454

Hall, J. (2009). @Time to develop my career? That's a fantasy! UK professional standards framework and ethical staff and educational development. In M. Laycock \& L. Shrives (Eds.), Embedding CPD in higher education. SEDA Paper 123 (Chapter 4, pp. 37-43). London: SEDA.

Higher Education Academy. (2011). UK professional standards framework for teaching and supporting learning. York: HEA. Retrieved from https://www.heacademy.ac.uk/sites/default/files/downloads/ ukpsf_2011_english.CPDf

King, H. (2004). Continuing professional practice development in higher education: What do HE teachers do? Planet, 13, 26-29.

Knowles, M. (1998). The adult learner (5th ed.). Houston, TX: Gulf Publishing Company.

Kynaston, R., \& Maynard, C. (2009). 'There just seemed so much to do.....' Using institutional processes to support the development of professional standards at Liverpool John Moores University. In M. Laycock \& L. Shrives (Eds.), Embedding CPD in higher education. SEDA Paper 123 (Chapter 6, pp. 53-61). London: SEDA. 
Mullins, L. J. (2016). Management and organisational behaviour (11th ed.). Harlow: Pearson Education Ltd.

Platt, A., \& Floyd, S. (2015). Preparing for the UKPSF at Ulster University: An exploration of the role the HE teacher manager plays in engaging and supporting staff preparedness for professional recognition. Educational Developments, 16, 5-10.

Quinn, L. (2012). Understanding resistance: An analysis of discourses in academic staff development. Studies in Higher Education, 37, 69-83.

Robson, C. (2011). Real world research (3rd ed.). Chichester: Wiley.

Rothwell, A. (2009). Embedding CPD: Policy implementation or research agenda? In M. Laycock \& L. Shrives (Eds.), Embedding CPD in higher education. SEDA Paper 123 (Chapter 1, pp. 13-19). London: SEDA.

Rothwell, A., \& Herbert, I. (2007). Accounting professionals and CPD: Attitudes and engagement. Research in Post Compulsory Education, 12, 121-138.

Seden, R., \& Cope, S. (2009). Reflections on piloting professional teaching standards: What have we learnt so far from beginning to implement our CPD framework. In M. Laycock \& L. Shrives (Eds.), Embedding CPD in higher education. SEDA Paper 123 (Chapter 6, pp. 63-70). London: SEDA.

Spowart, L., Turner, R., Shenton, D., \& Kneale, P. (2015).'But I've been teaching for 20 years...': Encouraging teaching accreditation for experienced staff working in higher education. International Journal for HE Teacher Development, 21(3), 206-218. doi:10.1080/1360144X.2015.1081595

Turner, N., Oliver, M., McKenna, C., Hughes, J., Smith, H., Deepwell, F., \& Shrives, L. (2013). Measuring the impact of the UK professional standards framework for teaching and supporting learning. York: HEA. Retrieved from https://www.heacademy.ac.uk/ukpsf-impact-study

Wood, P. (2008). Continuing professional development in higher education: A qualitative study of engagement in the field of nursing and midwifery. Journal for the Enhancement of Learning and Teaching, 4, 12-21. 